\title{
Circulating regulatory anti- $T$ cell receptor antibodies in patients with myasthenia gravis
}

\author{
Florence Jambou, ${ }^{1}$ Wei Zhang, ${ }^{2}$ Monique Menestrier, ${ }^{3}$ Isabelle Klingel-Schmitt, ${ }^{1}$ \\ Olivier Michel, ${ }^{4}$ Sophie Caillat-Zucman, ${ }^{5}$ Abderrahim Aissaoui, ${ }^{1}$ Ludovic Landemarre, ${ }^{4}$ \\ Sonia Berrih-Aknin, ${ }^{1}$ and Sylvia Cohen-Kaminsky ${ }^{1}$ \\ ${ }^{1}$ Centre National de la Recherche Scientifique (CNRS), Unité Mixte de Recherche (UMR) 8078 - Remodelage Tissulaire et \\ Fonctionnel: Signalisation et Physiopathologie, Institut Paris Sud sur les Cytokines (IPSC), Université Paris XI, \\ Hôpital Marie Lannelongue, Le Plessis-Robinson, France \\ ${ }^{2}$ Department of Clinical Neurology, Neuroscience Group, Institute of Molecular Medicine, John Radcliffe Hospital, \\ University of Oxford, Oxford, United Kingdom \\ ${ }^{3}$ Département d'Echographie, Hôpital Marie Lannelongue, Le Plessis-Robinson, France \\ ${ }^{4}$ AGRO-BIO SAS, La Ferté Saint Aubin, France \\ ${ }^{5}$ Service d'Immunologie Clinique, Hôpital Necker, Paris, France
}

Serum anti-T cell receptor (TCR) Ab's are involved in immune regulation directed against pathogenic $T$ cells in experimental models of autoimmune diseases. Our identification of a dominant $T$ cell population expressing the V $\beta 5.1$ TCR gene (TCRBV5-1), which is responsible for the production of pathogenic anti-acetylcholine receptor (AChR) autoantibodies in HLA-DR3 patients with earlyonset myasthenia gravis (EOMG), prompted us to explore the occurrence, reactivity, and regulatory role of anti-TCR Ab's in EOMG patients and disease controls with clearly defined other autoantibodies. In the absence of prior vaccination against the TCR, EOMG patients had elevated anti-V $\beta 5.1$ Ab's of the IgG class. This increase was restricted largely to EOMG cases with HLA-DR3 and with less severe disease, and it predicted clinical improvement in follow-up studies. EOMG patient sera containing anti-TCR Ab's bound specifically the native TCR on intact V $\beta 5$.1-expressing cells and specifically inhibited the proliferation and IFN- $\gamma$ production of purified V $\beta 5.1$-expressing cells to alloantigens in mixed lymphocyte reaction and the proliferation of a V $\beta 5.1$-expressing $\mathrm{T}$ cell clone to an AChR peptide, indicating a regulatory function for these Ab's. This evidence of spontaneously active anti-V $\beta 5.1 \mathrm{Ab}$ 's in EOMG patients suggests dynamic protective immune regulation directed against the excess of pathogenic V $\beta 5$.1-expressing T cells. Though not sufficient to prevent a chronic, exacerbated autoimmune process, it might be boosted using a TCR peptide as vaccine.

J. Clin. Invest. 112:265-274 (2003) doi:10.1172/JCI200316039.

\section{Introduction}

Autoreactive $\mathrm{T}$ cells form part of the normal repertoire. The nonresponsiveness of $\mathrm{T}$ cells to self-antigens is controlled by several mechanisms including clonal deletion, $\mathrm{T}$ cell anergy, $\mathrm{T}$ cell ignorance, and specific regulatory $\mathrm{T}$ $\left(\mathrm{T}_{\text {reg }}\right)$ cells $(1,2)$. One type of $\mathrm{T}_{\text {reg }}$ cell, the $\mathrm{T}$ cell receptor (TCR) peptide-specific regulatory CD4 T cell (anti-idiotypic $T$ cell), has been shown to play a key role in the

Received for publication May 30, 2002, and accepted in revised form May 6, 2003.

Address correspondence to: Sylvia Cohen-Kaminsky, CNRS UMR 8078, Hôpital Marie Lannelongue, 133 Avenue de la Résistance, 92350 Le Plessis-Robinson, France.

Phone: 33-1-40-94-29-94; Fax: 33-1-46-30-45-64;

E-mail: sylvia.kaminsky@ccml.u-psud.fr.

Conflict of interest: The authors have declared that no conflict of interest exists.

Nonstandard abbreviations used: regulatory $\mathrm{T}\left(\mathrm{T}_{\mathrm{reg}}\right) ; \mathrm{T}$ cell receptor (TCR); experimental autoimmune encephalomyelitis (EAE); myasthenia gravis (MG); early-onset myasthenia gravis (EOMG); acetylcholine receptor (AChR); Myasthenia Gravis Foundation of America (MGFA); complementarity-determining region 2 (CDR2); PBS containing $0.01 \%$ Tween 20 (PBST); mixed lymphocyte reaction (MLR). control of autoimmune diseases $(3,4)$. Anti-idiotypic T cells have been found in the unprimed immune system (5) as well as in the course of T cell or TCR vaccination in autoimmune diseases, and may arise as a consequence of the natural development of autoimmune $\mathrm{T}$ cells (reviewed in ref. 6). TCR-specific $\mathrm{CD}^{+} \mathrm{T}_{\text {reg }}$ cells may control pathogenic $\mathrm{CD}^{+} \mathrm{T}$ cells either directly or through $\mathrm{CD}^{+}$TCR-specific $\mathrm{T}_{\text {reg }}$ cells $(3,4,7,8)$. The action of these TCR-specific $T_{\text {reg }}$ cells at the molecular level may involve either cytotoxicity against autoreactive $\mathrm{T}$ cells (9-11) or a shift in the cytokine phenotype of the autoimmune response $(7,10,12,13)$. Striking similarities in the induction and characteristics of T cells specific for TCR peptides have been found in rodents and humans (3-13), supporting the generality of the observations.

Anti-TCR Ab's may constitute another significant level of regulation, but their occurrence and regulatory role have been poorly investigated, mainly in studies on TCR vaccination (14-19). Such Ab's may occur spontaneously at low levels in some healthy human sera and at higher levels in patients with rheumatoid arthritis and systemic lupus erythematosus (15). They were generally undetectable in MS patients $(16,17)$ and were found in 
some studies (18) but not others (19) in experimental autoimmune encephalomyelitis (EAE) before vaccination against autoreactive $T$ cells. They were consistently elevated after T cell or TCR vaccination in mice $(18,19)$, though rarely in vaccinated MS patients $(9,10,17)$. Recently, however, such patients proved to have B cells producing anti-idiotypic anti-TCR Ab's of the IgM class, with indications of potential regulatory properties (16).

Most of these studies have focused almost exclusively on T cell-mediated autoimmune diseases such as MS. For extending them to autoantibody-mediated disorders, myasthenia gravis (MG) provides a prototypic model $(20-22)$ with particularly well-defined target molecules $(23,24)$, patient subgroups, and immunopathology (20, $25,26)$. The pathogenic autoantibodies to the muscle acetylcholine receptor (AChR) cause AChR loss and defective neuromuscular transmission $(27,28)$. In patients with early-onset MG (EOMG; before age 40), there are strong female and HLA-DR3-B8 biases (20, 26, 29). Remarkably, there is also characteristic thymic hyperplasia with medullary germinal centers (30-32). Moreover, these thymi also contain all the partners required for autoantibody responses, including AChR (33-35) and activated AChR-sensitized T and B cells (36-41). Indeed, the symptoms generally improve after thymectomy in EOMG $(25,31,42)$. We have pinpointed a subpopulation of thymic T cells expressing the V $\beta 5.1$ TCR gene; these are expanded in the thymi of HLA-DR $3^{+}$MG patients and are preferentially located in the germinal centers, indicating participation in the autoantibody response (43). The pathogenicity of this cell population has been demonstrated in chimeric humanized SCID mice transplanted with MG thymic cells (44); the injection of antiVB5.1 Ab's prevented AChR loss and complement deposits at muscle end plates. Thymic cells depleted of V $\beta 5$.1-positive cells prior to cell transfer were nonpathogenic, indicating that V $\beta 55.1$-positive cells are involved in the production of pathogenic autoantibodies (44).

Taking advantage of this well-characterized pathogenic $\mathrm{T}$ cell population in EOMG patients, we have investigated immune regulation directed at TCR determinants in EOMG patients. We have found high levels of anti-V $\beta 5.1 \mathrm{IgG}$ Ab's in HLA-DR ${ }^{+} \mathrm{MG}$ patients, providing conclusive evidence for their spontaneous increase in the absence of prior TCR vaccination. Our data suggest that there is a natural regulatory process involving B cells directed at TCR determinants that may be boosted by TCR peptide vaccines, with potential implications for the treatment of MG.

\section{Methods}

Patients and clinical evaluation. With informed consent and Ethical Committee approval (Comité Consultatif de Protection des Personnes dans la Recherche Biomédicale, Kremlin Bicêtre, France), we studied MG patients undergoing thymectomy and followup at the Centre Chirurgical Marie-Lannelongue (Philippe Levasseur and Cyril Gaud, Department of Thoracic Surgery). They were selected using precise biological and clinical criteria to ensure comparability in a homogeneous patient group. All the patients were young (14 to 40 years of age) with recent disease onset (3 months to 1 year) at the time of thymectomy, with a hyperplastic thymus, a high anti-AChR Ab titer $(>10 \mathrm{nM})$, and generalized disease (i.e., affecting more than just the ocular muscles). About $80-90 \%$ of the MG patients in this group consistently are HLA-DR3 ${ }^{+}$, when recruited consecutively. Therefore, to make comparisons between HLA-DR3 ${ }^{+}$and HLA-DR3- patients possible, we deliberately recruited a larger number of HLA-DR3 ${ }^{-}$patients meeting the same criteria as the HLA-DR3 ${ }^{+}$patients. This strategy, selecting for recent disease and homogeneous clinical and biological criteria, has already been used to obtain comparable data for patients in the identification of pathogenic T cells (44). MG patients on prior corticosteroid treatment, which may influence immune function, were excluded from the study. In addition, we also tested sera from patients with other neurologic diseases and clearly defined autoantibodies other than anti-AChR including anti-GAD Ab (stiff man syndrome), anti-VGCC Ab (Lambert Eaton myasthenic syndrome), anti-GQ1b Ab (Miller Fisher syndrome), anti-GM1 Ab (Guillain Barré syndrome), anti-Hu and anti-Yo Ab (paraneoplastic disease), and anti-VGKC Ab (acquired neuromyotonia) (from the infirmary of John Radcliffe Hospital). Sera from agematched blood donors served as healthy controls. All MG patients were HLA-typed by a PCR method (45) and their anti-AChR Ab titer was determined at Hôpital Necker using human muscle AChR conjugated with ${ }^{125} \mathrm{I}$ - $\alpha$-bungarotoxin as the antigen (46). Serum IgG was titrated by immunoturbidimetry (Turbitimer; DadeBehring Inc., Deerfield, Illinois, USA). Disease severity was graded before knowledge of serological or HLA status and independently of our biological investigation by the same neurologist (Cyril Gaud) before and after thymectomy according to the Myasthenia Gravis Foundation of America (MGFA) clinical classification: class II, mild generalized muscle weakness; class III, moderate generalized muscle weakness; and class IV, severe generalized muscle weakness (47). Many patients also had ocular muscle weakness; those with bulbar muscle involvement are designated IIb, IIIb, or IVb, and those without are designated IIa, IIIa, or IVa (47).

Electromyography. Electromyographic studies were performed as previously described (48) by repetitive cubital nerve stimulation for $0.2 \mathrm{~ms}$ at a frequency of 20 cycles/s for $90 \mathrm{~s}$ (1,800 stimulations), recording at the muscle of the hypothenar eminence. This protocol is routinely used at Marie Lannelongue Hospital on large numbers of healthy controls and MG patients, resulting in the accurate calibration of normal values in our experimental conditions. The amplitude and the latency of the response were measured. Normal values were around $40 \%$ for amplitude and about $1.0 \pm 0.1 \mathrm{~ms}$ for latency. In MG patients, amplitude decreased to less than $40 \%$ and the latency of the response was greater than normal. 
Peptides. We selected TCR V $\beta 5.1, \mathrm{~V} \beta 6.7$, and V $\beta 14$ peptides on the basis of their predicted immunogenicity using Epiplot (http://solea.quim.ucm.es/ mag/) and Antheprot (http://antheprot-pbil.ibcp.fr/) software, plus the TCR amino acid sequences available from the International ImMunoGeneTics database (IMGT) website. The peptides were synthesized by Neosystem SA (Strasbourg, France). According to the nomenclature of IMGT, TCR V $\beta 5.1$ CDR2 peptide (TPGQGLQFLFEYFSETQRNKG) contains portions of the framework 2 and framework 3 regions and complementarity-determining region 2 (CDR2). The adjacent TCR, V $\beta 5.1$ CDR1 (CSPISGHRSVSWYQQT), includes the CDR1 region. Lyophilized peptides (purity greater than 95\%) were dissolved in sterile water and stored frozen in aliquots at $-20^{\circ} \mathrm{C}$ until use. As controls, we used immunogenic peptides containing the CDR2 region of TCR VB6.7 (PGKGLRLIYYSVAAALTDKG) and TCR V $\beta 14$ (VMGKEIKFLLHFVKESKQDES): these TCRs have frequencies similar to V $\beta 5.1$ and no bias in frequency in thymic versus peripheral blood $\mathrm{T}$ cells and thus no sign of involvement in EOMG, unlike V $\beta 5$.1. A peptide containing the CDR2 of mouse $\operatorname{IgG}$ (ASRNKANDYTTEYSASVKGRFIVS) was used as an irrelevant peptide (49).

Detection of anti-TCR Ab's by ELISA. Sera, stored at $-40^{\circ} \mathrm{C}$, were heat-inactivated at $56^{\circ} \mathrm{C}$ for 30 minutes, dispensed in aliquots, and stored frozen at $-20^{\circ} \mathrm{C}$. Sera were serially diluted from 1:10 to 1:5000 and tested in duplicate wells. MaxiSorp Nunc plates (Polylabo Merck Eurolab SA, Fontenay sous Bois, France) were incubated with $1 \mu \mathrm{g}$ of peptide in $200 \mu \mathrm{l}$ of $0.05 \mathrm{M}$ carbonate-bicarbonate solution, $\mathrm{pH} 9.6$, for 60 minutes at $37^{\circ} \mathrm{C}$ and overnight at $4^{\circ} \mathrm{C}$. The wells were washed three times with PBST (PBS, 0.01\% Tween 20) and incubated sequentially for 1 hour at $37^{\circ} \mathrm{C}$ with $200 \mu \mathrm{l}$ of: blocking solution (PBST, 5\% BSA), diluted serum, biotinylated goat anti-human IgG Ab (1:5,000; Jackson, Beckman Coulter, Marseille, France), and streptavidin-peroxidase (1:10,000; Immunotech, Beckman Coulter, Marseille, France), with three PBST washes between each step. After a final wash with PBS, the color was developed at room temperature with o-phenylenediamine dihydrochloride substrate (OPD; Sigma-Aldrich, Saint Quentin Fallavier, France) and $\mathrm{H}_{2} \mathrm{O}_{2}$ and stopped with $3 \mathrm{~N} \mathrm{HCl}$. OD was measured at $490 \mathrm{~nm}$ using an automated microplate reader (Titertek Multiscan; Thermo Labsystems, Cergy Pontoise, France). Titers were derived from the linear portion of the curves and were defined as the reciprocal of the dilution at which the OD value was 0.2 (see inset in Figure 1a). Any values below this range were assigned an arbitrary titer of 20 . Total IgG's were purified from the sera of MG patients by affinity chromatography on protein G-Sepharose (Amersham Pharmacia Biotech, Saclay, France). They were tested by the ELISA method, as described above. The specificity of the ELISA was evaluated by incubating the sera or total IgG with various quantities of V $\beta 5.1$
CDR2 peptide (0-250 $\mathrm{nM}$ ) for 1 hour at $37^{\circ} \mathrm{C}$ before adding the mixture to wells coated with the CDR2 peptide and going through the ELISA procedure.

Surface plasmon resonance procedures. Biacore measurements were performed with a Biacore J apparatus (Biacore $\mathrm{AB}$, Uppsala, Sweden). The CM5 sensor chip, the amine coupling kit, and HBS-Ep Biacore buffer $(0.01 \mathrm{M}$ HEPES, 3 mM EDTA, pH 7.4, $0.15 \mathrm{M} \mathrm{NaCl}$, and $0.005 \%$ $\mathrm{vol} / \mathrm{vol}$ surfactant $\mathrm{P} 20$ ) were obtained from Biacore $\mathrm{AB}$. All experiments were performed at $25^{\circ} \mathrm{C}$ and HBS-Ep was used as the running buffer. V $\beta 5.1$ CDR2 peptide was coupled to BSA (Perbio Science France, Bezons, France) with glutaraldehyde (50). The sensor chip was activated by application of a $\mathrm{v} / \mathrm{v}$ mixture of $N$-hydroxysuccinimide $(0.4 \mathrm{M})$ and 1-ethyl-3-(3-dimethylaminopropyl)arbodiimide hydrochlorid $(0.1 \mathrm{M})$ at a flow rate of $30 \mu \mathrm{l} / \mathrm{min}$ for 6 minutes. V $\beta 5.1$ CDR2 peptide coupled to BSA was then immobilized on the CM5 sensor chip at a concentration of $100 \mu \mathrm{g} / \mathrm{ml}$ in $10 \mathrm{mM}$ acetate buffer ( $\mathrm{pH} 4.5$ ) at a flow rate of $30 \mu \mathrm{l} / \mathrm{min}$ for 6 minutes. The peptide was stabilized with $1 \mathrm{M}$ ethanolamine applied at a flow rate of $30 \mu \mathrm{l} / \mathrm{min}$ for 6 minutes, as described by the manufacturer (Biacore AB, Uppsala, Sweden), resulting in a mean signal of 4,363 resonance units on flow cell 1 . BSA $(100 \mu \mathrm{g} / \mathrm{ml}$ in acetate buffer, $\mathrm{pH} 4.5$ ) was immobilized at a flow rate of $30 \mu \mathrm{l} / \mathrm{min}$ for 6 minutes on flow cell 2 ; this was used as a control for nonspecific binding and bulk effects. Each sample (serum or purified IgG) was diluted in HBS-Ep Biacore buffer supplemented with $1 \mathrm{mM}$ carboxymethyldextran (Sigma-Aldrich) to reduce nonspecific binding to the sensor chip surface, and then injected at a flow rate of $15 \mu \mathrm{l} / \mathrm{min}$ for 3 minutes, followed by dissociation in buffer flow. After the dissociation phase, the sensor chip was regenerated by injecting $15 \mu \mathrm{l}$ of $1 \mathrm{mM} \mathrm{NaOH}$ at a flow rate of $15 \mu \mathrm{l} / \mathrm{min}$ for 1 minute. We tested the specificity of anti-V $\beta 5.1$ binding by preblocking the purified IgG or serum for 30 minutes at $37^{\circ} \mathrm{C}$ with various quantities ( 0 to $70 \mathrm{nM}$ ) of the V $\beta 5.1$ CDR2 peptide coupled to BSA before loading as described above. We observed no significant nonspecific binding, but we nonetheless subtracted the background on flow cell 2 from the sensorgrams prior to analysis, using Biaviewer version 3.1 software (Biacore AB).

$T$ cell proliferation assays. Clone PM-A1 (V $\beta 5.1 \mathrm{~T}$ cell clone) was maintained by restimulation with recombinant AChR $(\alpha 3-181)(0.05 \mu \mathrm{g} / \mathrm{ml})$ plus irradiated subtype 0401 HLA-DR $^{+}$peripheral blood lymphocytes every 13-15 days, and expansion with IL-2 every 3-4 days thereafter, as previously described (51). For proliferation assays, $3 \times 10^{4}$ well-rested $\mathrm{T}$ cells were cultured in duplicate with $1 \times 10^{5}$ to $2 \times 10^{5}$ irradiated peripheral blood lymphocytes plus the $\alpha 3-181$ AChR in RPMI 1640 medium (Sigma-Aldrich) in the presence or absence of serum from HLA-DR $3^{+}$and HLA-DR3- EOMG patients for 48 or 72 hours. $\left[{ }^{3} \mathrm{H}\right]$ Methylthymidine (Amersham International, Amersham, United Kingdom) was added to the wells for the last 18 hours of culture. The radioactivity on 
the plate was then counted on a Betaplate flatbed liquid scintillation counter (PerkinElmer Life Science, Courtaboeuf, France).

In the mixed lymphocyte reaction (MLR) inhibition assay, responder cells were purified according to their TCR expression using FITC-conjucated anti-V $\beta$ Ab's (Immunotech, Beckman Coulter) and anti-FITC beads (Miltenyi Biotec, Paris, France) and then incubated overnight at $37^{\circ} \mathrm{C}$ in culture medium to allow proper expression of TCR. Purified responder cells $\left(2 \times 10^{4}\right)$ were treated with serum (1:50 in RPMI 1640 medium) from HLA-DR3 ${ }^{+}$EOMG patients or from healthy controls at $4^{\circ} \mathrm{C}$ for 2 hours, then washed with medium three times. As a control in the MLR inhibition assay, the responder cells were treated with medium alone. The proliferation assay was carried out using the serum-treated responder cells and $1 \times 10^{5}$ irradiated ( $90 \mathrm{~Gy}$ ) stimulator peripheral blood lymphocytes (pooled from five healthy donors) in $200 \mu \mathrm{l}$ RPMI 1640 supplemented with $10 \% \mathrm{AB}$ serum. Cells were plated in 96 -well round-bottomed microtiter plates at $37^{\circ} \mathrm{C}$ in an incubator in $5 \% \mathrm{CO}_{2}$. On day 5 , supernatants from triplicate wells were harvested and frozen at $-80^{\circ} \mathrm{C}$ for later cytokine analysis and the cells were incubated with $1 \mu \mathrm{Ci}\left[{ }^{3} \mathrm{H}\right]$ thymidine $(6.7 \mu \mathrm{Ci} / \mathrm{mM})$ for 18 hours. Cells were then harvested and ${ }^{3} \mathrm{H}$ incorporation was determined by liquid scintillation counting.

Cytokine-specific ELISA. IFN- $\gamma$ and IL-4 levels in MLR culture supernatants were determined using sensitive ELISA kits (IL-4 from Amersham Biosciences Europe, Orsay, France; IFN- $\gamma$ from Pierce Endogen, Perbio Science France) according to the manufacturers.

Flow cytometry. The binding of anti-TCR Ab to intact $\mathrm{T}$ cells was assayed by flow cytometry. In all cases, cells to be labeled were determined to be at least $90 \%$ viable and $1 \times 10^{6}$ cells were used. Cells were incubated for 2 hours on ice with purified IgG from control and MG sera, preblocked or not with the VB5.1 CDR2 peptide as described above. For staining amplification, after incubation with biotinylated human anti-IgG $\mathrm{Ab}$, the cells were incubated sequentially for 10 minutes at room temperature with streptavidin-HRP, biotinylated tyramide in amplification medi$\mathrm{um}$, and streptavidin-PE, following the manufacturer's instructions (EAS kit, Flow-Amp System Ltd.; Beckman Coulter, Marseille, France). Cells were washed and resuspended in $300 \mu \mathrm{l}$ PBS. The fluorescent staining of the cells was measured using a FACScan (Becton, Dickinson and Co., Le Pont de Claix, France). Data were analyzed with CellQuest software (Becton, Dickinson and Co.). Intact cells were

\section{Figure 1}

gated and 100,000 events were collected; the $\mathrm{D} / \mathrm{s}(\mathrm{n})$ value (calculated from Kolmogorov-Smirnov statistics and defined as an index of similarity for two curves) was used in the analysis of flow cytometry data.

Statistical analysis. The nonparametric Mann-Whitney test was used throughout for comparison between patient subgroups, and the Kolmogorov-Smirnov test was used for flow cytometry data analysis.

\section{Results and Discussion}

This study addresses the fundamental questions of whether regulation directed at TCR determinants occurs spontaneously in the absence of prior vaccination in
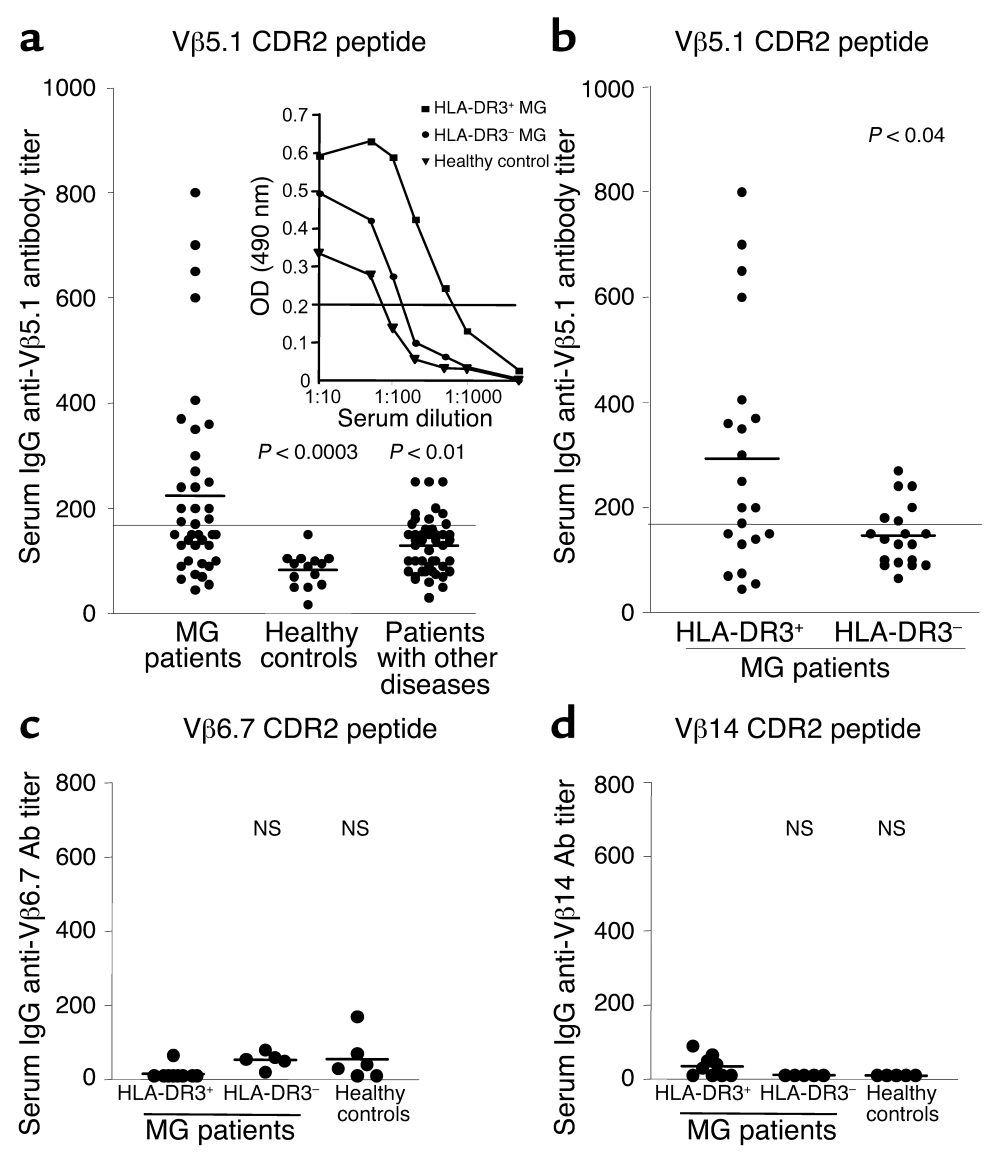

Serum IgG Ab's against TCR peptides in controls and EOMG patients with or without HLA-DR3 determined by ELISA. Titrations were carried out with serial dilutions of serum from 1:10 to 1:5,000. Sample dilutions were run in duplicate for each individual. The titer was the reciprocal of the dilution giving an OD of 0.2 in the linear portion of the curve in the inset in (a), where representative titers were 90, 120, and 700 for a healthy control, an HLA-DR3- MG patient, and an HLA-DR3 ${ }^{+}$MG patient, respectively. (a) We tested sera from $M G$ patients who had not undergone prior TCR vaccination $(n=40)$, age-matched healthy controls $(n=14)$, and patients with other clearly defined autoantibodies $(n=46)$. The horizontal line corresponds to the mean titer of healthy controls + $2.6 \mathrm{SD}$. To compare with the EOMG patients, we used the Mann-Whitney test. (b) Anti-V $\beta 5.1$ Ab titers in EOMG patients with or without HLA-DR3. Serum titers of Ab's against CDR2 peptides from $\mathrm{V} \beta 6.7$ (c) or $\mathrm{V} \beta 14$ (d) in HLA-DR3 ${ }^{+}$EOMG patients $(n=10)$, HLA-DR3EOMG patients $(n=5)$, and healthy controls $(n=6)$. The $P$ values indicated in $\mathbf{b}-\mathbf{d}$ were calculated versus the HLA-DR3 ${ }^{+}$MG patient group. Each point corresponds to an individual patient. Horizontal bars indicate the mean. 
patients with autoimmune diseases and whether it extends to autoimmune diseases other than MS. We reasoned that a clear definition of a pathogenic $\mathrm{T}$ cell population in MG would make it easier to identify any regulatory mechanisms occurring spontaneously. Our studies of the thymic $\mathrm{T}$ cell repertoire (43) and activation (38) combined with the use of a SCID mouse model in a selected homogeneous group of $\mathrm{MG}$ patients (44) made it possible to pinpoint V $\beta 5.1$ expressing cells as pathogenic $\mathrm{T}$ cells involved in the control of pathogenic anti-AChR autoantibodies. We therefore searched for anti-TCR Ab's against pathogenic V $\beta 5$.1-expressing T cells in MG patients who had not undergone any prior vaccination.

$A n t i-V \beta 5.1 A b$ 's are found at higher levels in the sera of HLA-DR3 MG patients and are induced Ab's restricted to $M G$. We set up a sensitive ELISA using a TCR V $\beta 5.1$ CDR2 peptide to detect spontaneous IgG anti-V $\beta 5.1$ $A b$ 's in sera from $M G$ patients. Their titers proved to be significantly higher (mean titer \pm SEM, $228.2 \pm 29.1$, median 150) than those of healthy controls (mean value, $83 \pm 8.8$, median 92.5) $(P<0.0003)$ (Figure 1a). Similar data were obtained with a TCR V $\beta 5.1$ CDR1 peptide, although the titers were often slightly lower (not shown). Therefore we focused on the CDR2 peptide, knowing that the CDR2 region is clearly highly antigenic and exposed in TCRs on the cell surface and that an isolated CDR2 peptide might adopt a secondary structure similar to that of the native CDR2 region from which it was derived (52). Evidently, these Ab's to CDR2 peptide are increased spontaneously and early in the course of EOMG (all patients had recent disease development, less than 1 year ago), indicating a coincident event with disease development as already discussed for $\mathrm{T}_{\text {reg }}$ directed to TCR (6). Moreover, the antiV $\beta 5.1$ titers were significantly higher in patients with HLA-DR3 (mean titer \pm SEM, $305.5 \pm 48.7$, median 250) than in those without (mean value $156.8 \pm 15.9$, median 145) $(P<0.04)$ (Figure 1b), as predicted from the selective involvement of pathogenic $V \beta 5.1^{+} \mathrm{T}$ cells in HLA-DR3 ${ }^{+}$patients $(43,44)$.

We next assessed disease specificity by testing for anti-V $\beta 5.1 \mathrm{Ab}$ 's in patients with other autoimmune syndromes and autoantibodies to clearly defined targets other than AChR. Their anti-V $\beta 5.1 \mathrm{Ab}$ titers proved to be significantly lower (mean titer \pm SEM, $129.1 \pm 7.8$, median 135; $P<0.01$ ) (Figure 1a). Moreover, this $\mathrm{Ab}$ response was also $\mathrm{V} \beta 5.1$-specific: there was no significant recognition of analogous CDR2 peptide from the $V \beta 6.7$ and $V \beta 14$ sequences even in HLA-DR $3^{+}$ cases (Figure 1, $\mathrm{c}$ and $\mathrm{d}$ ), and only marginal reactivity with an IgG CDR2 peptide, regardless of HLA-DR3 status (not shown). Thus, HLA-DR3 ${ }^{+}$MG patients presented a specific increase in the titer of anti-V $\beta 5.1 \mathrm{Ab}$ 's. The higher titers of anti-V $\beta 5.1 \mathrm{Ab}$ 's in HLA-DR3 ${ }^{+} \mathrm{MG}$ patients than in HLA-DR3- MG patients and healthy controls, but not of anti-V $\beta 6.7$ and anti-V $\beta 14 \mathrm{Ab}$ 's, provides further evidence of a link between HLA-DR3 background and V $\beta 5$.1-expressing cells.
Our data are consistent with data from previous studies on EAE and MS patients demonstrating the presence of Ab's directed against CDR2. Specific anti-TCR Ab's represent only a small fraction of serum Ig's, which may account for the difficulties in detecting them. Indeed such Ab's were generally detected only in TCR peptide-immunized individuals (16-19). In contrast, we detected a spontaneous increase in the levels of such Ab's in MG patients in the absence of immunization, consistent with the notion that these $\mathrm{Ab}$ 's are induced naturally during the course of the disease. Other studies have reported the presence of Ab's against the CDR1 but not the CDR2 peptide in systemic lupus erythematosus and rheumatoid arthritis patients (15), and during the course of viral infection in mice and humans (53-55). These differences may be due to the arbitrary scanning of the whole TCR chain and the use of synthetic 16-mer peptides overlapping by five residues, an approach that may miss potential immunogenic regions $(15,56)$. In contrast, we used a candidate peptide approach involving the use of prediction software to identify immunogenic epitopes. Recently, anti-CDR3 Ab's (anti-clonotypic Ab's) were also found in MS patients following immunization with TCR peptides (16), indicating diversity of the anti-TCR humoral response. This diversity has also been shown for the anti-TCR $T$ cell immune response, which targets many immunogenic TCR regions, including the CDR3 region $(4-6,8)$. Therefore cellular and humoral immunity against all immunogenic TCR regions, including CDR1, CDR2, and CDR3, probably occurs in healthy individuals and may be increased in patients. The mechanism of their triggering is still debated and remains to be elucidated (4-6).

Almost all the anti-V $\beta 5.1$ binding activity detected by ELISA proved to be in the IgG fraction eluted from protein $\mathrm{G}$ (Figure 2a), and it was clearly blocked by preincubation with the CDR2 peptide (Figure $2 b$ ), indicating that the IgG anti-V $\beta 5.1$ binding activity of MG sera was specific. In addition we were able to detect peptideAb complex formation in real time by surface plasmon resonance analysis, although it was clear that these specific anti-TCR Ab's may represent a small fraction in a complex mixture of Ab's with different binding characteristics. Both sera and purified IgG dose-dependently bound to immobilized V $\beta 5.1$ peptide (Figure 2c). Again binding was blocked by preincubation with the BSA-conjugated V $\beta 5.1$ CDR2 peptide (Figure 2d).

An important issue was to determine whether circulating anti-V $\beta 5.1 \mathrm{Ab}$ 's from patients would specifically bind to the intact TCR on the surface of T cells. Since the anti-V $\beta 5.1 \mathrm{Ab}$ 's may represent a small fraction of the total IgG, we used staining amplification and flow cytometry analysis to show that purified IgG from MG sera indeed bound the intact TCR on the surface of purified VB5.1-expressing T cells (Figure 2, e-g). The fluorescent signal was significantly higher using purified IgG's from HLA-DR3 ${ }^{+}$MG sera with high anti-V $\beta 5.1$ titer compared with purified IgG's from control sera (Figure 2, e and f). Using Kolmogorov-Smirnov statistics, 


\section{Figure 2}

Kinetics and specificity of the binding of IgG's purified from serum against $V \beta 5.1$ CDR2 peptide or against intact $T$ cells, as measured by ELISA ( $\mathbf{a}$ and $\mathbf{b}$ ), surface plasmon resonance ( $\mathbf{c}$ and $\mathbf{d}$ ), and flow cytometry (e, $\mathbf{f}$, and $\mathbf{g}$ ). (a) Reactivity in the protein G-purified IgG (solid lines) and in the IgG-depleted fractions (dotted lines) as assessed by ELISA. (b) Blocking of ELISA reactivity by preincubating an IgG fraction with the V 35.1 CDR2 peptide (solid lines, $2.5 \mathrm{nM}$ [circles], 25 $\mathrm{nM}$ [triangles], and $250 \mathrm{nM}$ [squares]). Curves with no blocking peptide (dotted line) and with $2.5 \mathrm{nM}$ peptide are superimposed. (c) Sensorgrams illustrating the $V \beta 5.1$-binding activity of serum (1:100) and purified IgG from an HLA-DR3 ${ }^{+}$MG patient to the BSA-conjugated V $\beta 5.1$ CDR2 peptide. The increase in surface plasmon resonance signal indicates $A b$ binding to the $V \beta 5.1$ CDR2 peptide-BSA (relative to BSA alone) over 100 seconds. (d) Inhibition of binding of the $500 \mu \mathrm{g} / \mathrm{ml}$ purified $\lg G$ fraction with increasing concentrations of BSA-conjugated V $\beta 5.1$ CDR2 peptide $(3.5,7,35$, and $70 \mathrm{nM})$. (e) Binding of purified IgG's from two control sera ( $\mathrm{C} 1$ and $\mathrm{C} 2$, anti-V $\beta 5.1$ $\mathrm{Ab}$ titers 50 and below 20, respectively) (bold lines) compared with the control staining (thin line). (f) Binding of purified IgG's from two MG sera with high anti-V $\beta 5.1 \mathrm{Ab}$ titer $(\mathrm{MG} 1=800$ and $\mathrm{MG} 2=700$, respectively) (bold lines) compared with control staining (thin line). (g) Binding of purified IgG's from the MG1 serum (bold line) compared with control staining (thin line) and with staining with the same MG serum preincubated with the V $\beta 5.1$ CDR2 peptide (dotted line). RU, resonance units.

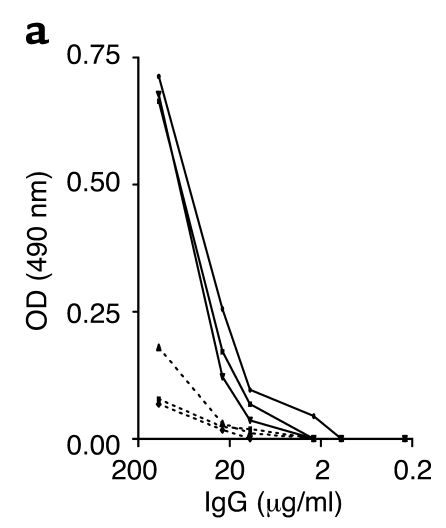

b
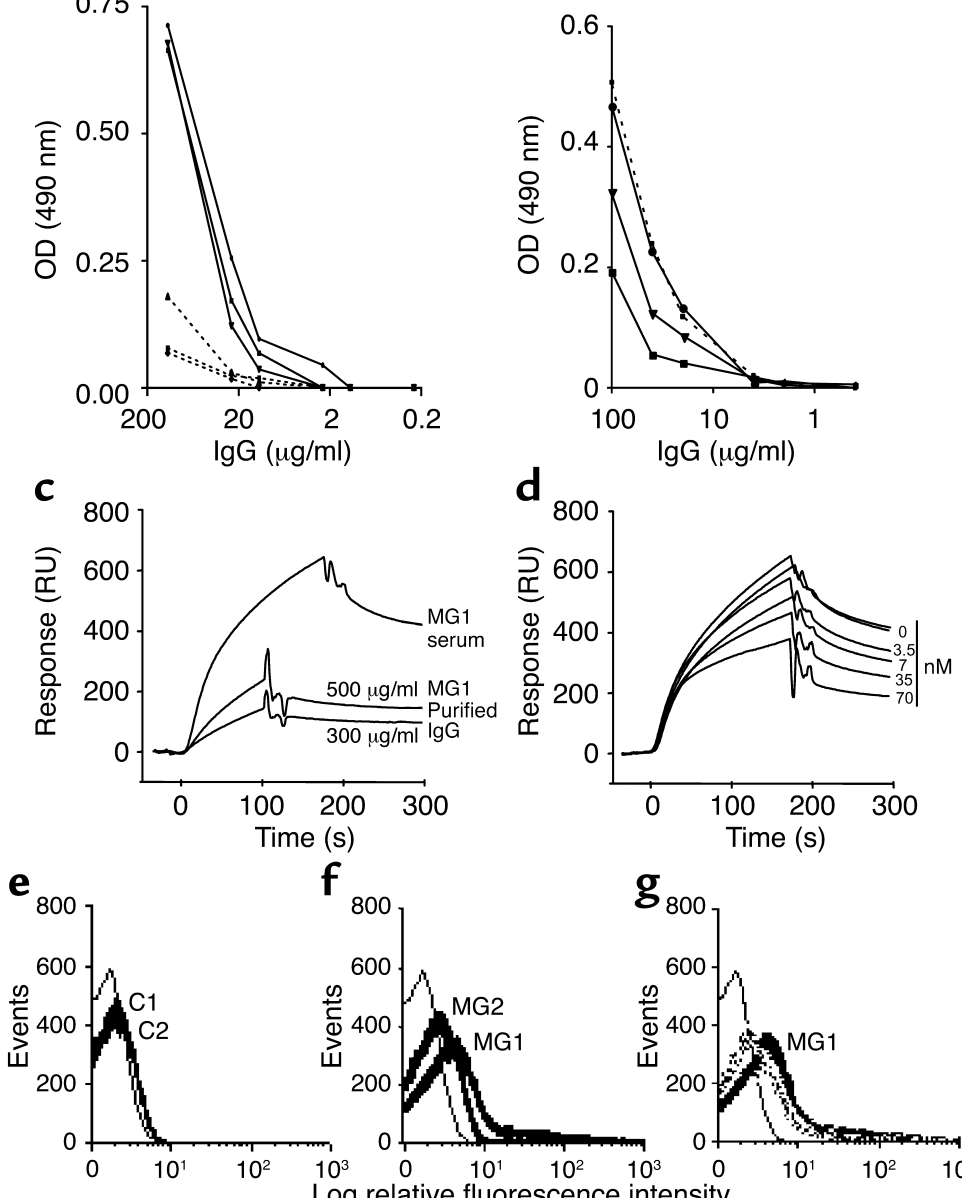

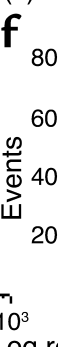

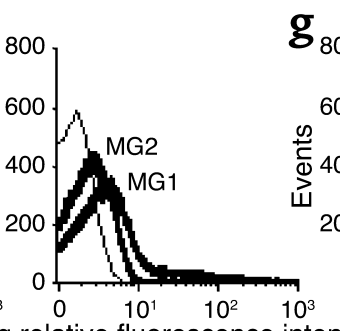

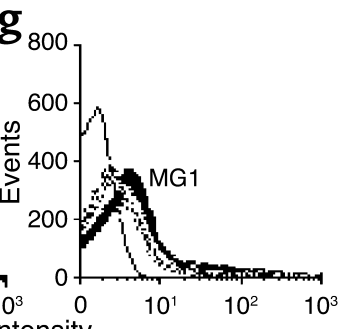

by comparison with the negative control staining, the calculated $\mathrm{D} / \mathrm{s}(\mathrm{n})$ values were $108.44(P<0.001)$ and $66.66(P<0.001)$ for MG1 and MG2 patients respectively (Figure 2f) compared with $32.51(P<0.001)$ and 27.36 $(P<0.001)$ for the two healthy controls C1 and C2 respectively (Figure 2e). Interestingly, the highest median channel shift was observed with the MG serum showing the highest anti-V $\beta 5.1 \mathrm{Ab}$ titer (MG1). In addition, the staining was specific since it was significantly inhibited by preincubation of the purified IgG's with the V $\beta 5.1$ CDR2 peptide, as assessed by a significant shift in the fluorescent signal, which had a D/s(n) value of 48.44 $(P<0.001)$ (Figure 2g). These data strongly suggested that anti-V $\beta 5.1 \mathrm{Ab}$ 's could have a functional role mediated by binding to the intact TCR on the cell surface.

It should be mentioned that in addition to IgG, IgM directed against the V $\beta 5.1$ CDR2 peptide was detected but showed similar levels in controls and EOMG patients with or without HLA-DR3 (not shown). The detection of IgG directed against the CDR2 peptide, in addition to IgM (and at higher levels in a particular subgroup of patients), is consistent with the view that anti-TCR Ab's are actively produced and their increase is induced during the course of the disease. The successful detection of anti-TCR Ab's directed against the
CDR2 region at low levels in healthy controls (and at increased levels in MG patients) indicates that antiTCR Ab's are present before the onset of the disease, as already demonstrated for anti-TCR $\mathrm{T}_{\text {reg }}$ cells(4-6).

Our results contrast with those of studies of MS in which anti-TCR Ab's directed against CDR2 were detected, but only after immunization with TCR peptides, in only two of 11 patients (17). However, while most of the patients in that MS study were HLA-DR2 ${ }^{+}$, the authors did not select their patients, most of whom had chronic progressive disease of long duration (mean of 18 years) and late onset. These factors could all decrease the prevalence of such anti-TCR Ab's. The authors also used a less sensitive ELISA (direct rather than indirect detection). Only after B cell isolation (EBV cell lines) from vaccinated patients was the occurrence of anti-idiotypic humoral response (at least of the IgM class) shown (16). Our study is the first to show an increase in the titer of anti-TCR Ab's of the IgG class in the absence of TCR peptide immunization in patients with an autoimmune disease. This was made possible by selecting a homogeneous group of patients and focusing on a pathogenic V $\beta 3$.1-expressing $T$ cell population expressing a disease-relevant TCR that may be targeted by these anti-TCR Ab-mediated regulatory 


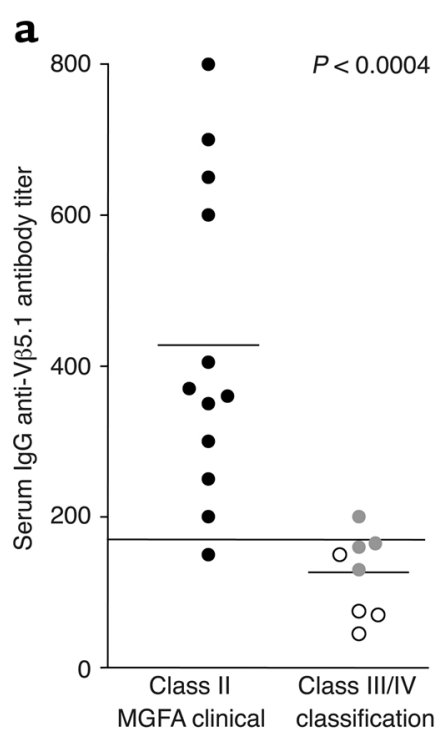

b Antibody titers

EMG
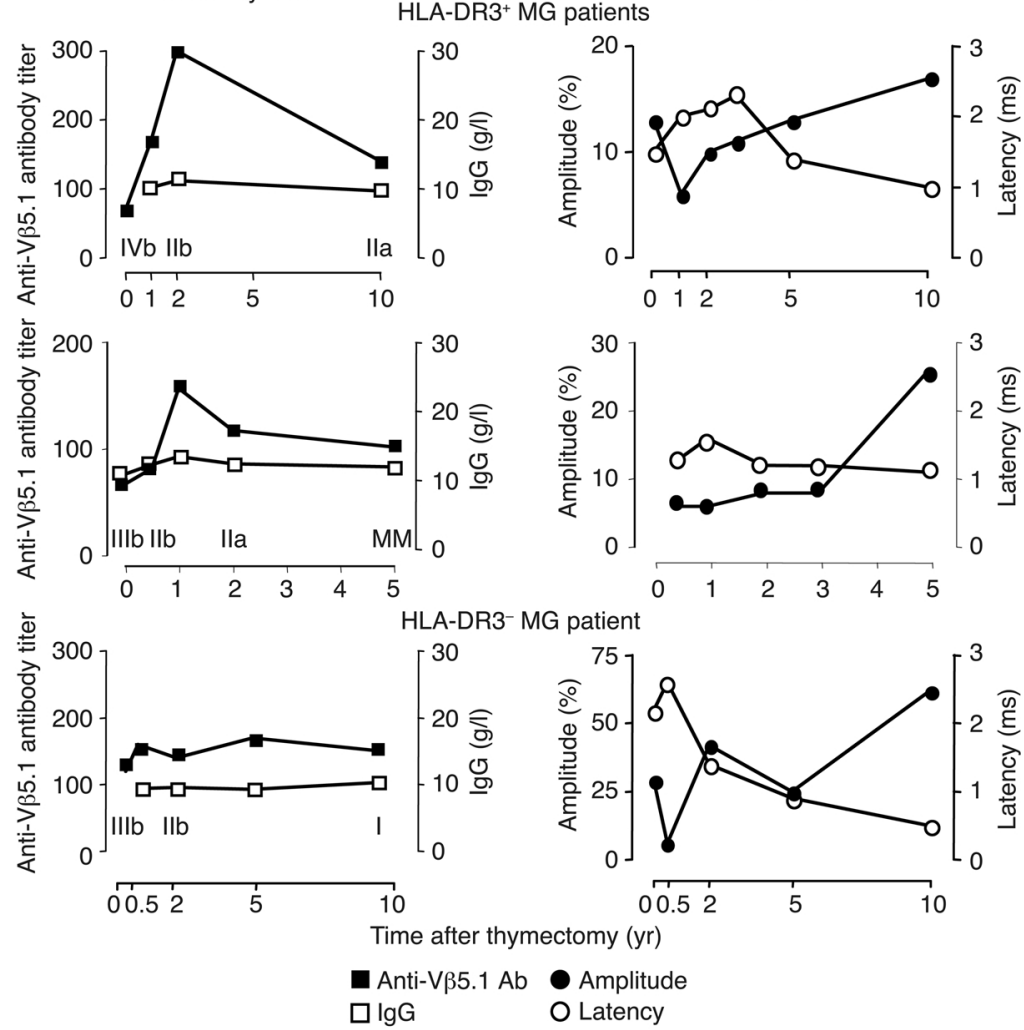

Figure 3

Anti-V $\beta 5.1$ Ab titers, disease severity (a), and outcome (b). (a) Anti-V $\beta 5.1$ IgG Ab titers in patients with mild (class II; black circles) $(n=12)$, moderate (class III; gray circles), or severe (class IV; white circles) $(n=9)$ generalized weakness (MGFA clinical classification). The horizontal line corresponds to the mean titer of healthy controls + 2.6 SD. Each point represents an individual patient. The nonparametric Mann-Whitney test was used to assess statistical significance. (b) Changes in anti-V $\beta 5.1 \mathrm{Ab}$ titer and clinical signs and electromyographic (EMG) features in patients with or without HLA-DR3. Representative examples from longitudinal studies in HLA-DR3 ${ }^{+}(n=4)$ and HLA-DR3- patients $(n=2)$. Electromyographic and serological assessments over 10 years are shown, including MGFA classification (bold characters near baselines). The normal amplitude in electromyography is more than $40 \%$. The normal latency value is around $1.0 \pm 0.1 \mathrm{~ms}$. MM, minor manifestations.

mechanisms. The pathogenic T cells continuously generated by the thymus $(43,44)$ may well be involved in the increase of these anti-TCR Ab's to high levels.

Anti-V $\beta 5.1$ Ab titer correlates with disease severity and outcome. We investigated the potential effects of the antiTCR Ab's by analyzing their clinical correlates. No correlation was found with anti-AChR Ab titers (not shown), which themselves are well known to correlate poorly with disease severity $(20,25,28)$. Interestingly, 11 of the $12(92 \%)$ HLA-DR $3^{+}$patients with mild (class II) disease showed elevated anti-V $\beta 5.1 \mathrm{Ab}$ titers versus only one of nine $(11 \%)$ with moderate or severe (class III and IV) disease $(P<0.0004)$ (Figure 3a). The higher anti-V $\beta 5.1 \mathrm{Ab}$ levels in the patients with mild disease indicate that they may have a protective role.

We further investigated the function of the anti-TCR $A b$ 's by monitoring anti-V $\beta 5.1$ Ab levels periodically after thymectomy in four patients with HLA-DR3 and in two without. As shown in detail for representative patients, a transient rise in titer coincided with a regression of the electromyographic signs (which are objective evidence of the clinical state) in HLA-DR3 ${ }^{+}$patients only (Figure $3 b$ ), and preceded a reduction of bulbar weakness and clinical improvement as assessed by disease grading. This rise was not observed in HLA-DR3- patients, although both HLA-DR3 ${ }^{+}$patients and HLA-DR3- patients showed improvements in symptoms 6 months to 1 year after thymectomy (Figure 3b). Although BV5S1 has been implicated in the SCID mouse model as disease-associated in HLA-DR $3^{+}$MG patients, it should be mentioned that other BV genes could also potentially be involved and might induce $\mathrm{Ab}$ 's as well, both in HLA-DR $3^{+}$and HLA-DR3- patients. This may explain the fact that HLADR $3^{-}$patients also improve clinically after thymectomy, even though no changes in anti-V $\beta 5.1 \mathrm{Ab}$ 's are detected.

A balance between regulators and pathogenic effectors has already been discussed in the course of $\operatorname{EAE}(12,57)$. Similarly, in MG, the increase in anti-V $\beta 5.1 \mathrm{Ab}$ titer after thymectomy is in accordance with the establishment of a new balance between regulatory mechanisms (TCR peptide-reactive regulatory cells and Ab's) and pathogenic V $\beta 5$.1-expressing cells following elimination of their source by thymectomy. While the thymus is also a source of regulatory $\mathrm{T}$ cells that can decrease total Ig production $(1,2)$, their loss seems an unlikely explanation for the present findings, because total serum IgG levels 
remained constant after thymectomy (Figure $3 b$ ). The observation of a transient rise in anti-CDR2 $\mathrm{Ab}$ titers in parallel with the improvement of disease symptoms is in accordance with our observations in experimental autoimmune MG (work in progress). This is also in agreement with studies in EAE showing that anti-V $\beta 8.2$ $\mathrm{CDR} 2$ peptide ( $\mathrm{p} 39-59$ ) Ab levels continue to increase for several days after challenge with myelin basic protein, reach a peak at the height of clinical improvement, and decrease to low levels after recovery from disease (18). Overall, these data demonstrate that anti-TCR Ab levels vary with the clinical state of the patients. High anti-V $\beta 5.1 \mathrm{Ab}$ titers are associated with a better clinical state, and hence better control of the disease, strongly suggesting a functional protective role of these Ab's. Therefore anti-TCR Ab's produced naturally during the course of MG may act as regulators of the disease, controlling and targeting the excess of V $\beta 5.1$ pathogenic T cells.

A functional role for anti-V $\beta 5.1 \mathrm{Ab}$ 's. Finally we tested for functional effects on proliferative responses of an AChR-specific $\mathrm{T}$ cell clone expressing V 35.1 (PM-A1) previously derived from the thymus of an EOMG patient (51). Sera from EOMG patients with HLA-DR3 (with high anti-V $\beta 5.1 \mathrm{Ab}$ titers) inhibited these responses dose-dependently (Figure $4 \mathrm{~b}$ ), and more consistently and efficiently (36-74\%) than those without (with low anti-V $\beta 5.1 \mathrm{Ab}$ titers $)(18-37 \%)(P<0.002$; Figure $4 a)$, again indicating a regulatory role. No correlation was found between the antiAChR Ab titer and the inhibitory activity of MG sera, indicating that anti-AChR may not contribute to the inhibitory effect of the sera. These data are consistent with the inhibitory activity of anti-TCR Ab's observed in the recovery phase of EAE (18) and in MS patients immunized with the TCR peptide (16). Our results extend these observations to human MG. The more potent inhibition mediated by HLA-DR3 ${ }^{+}$MG sera than by HLA-DR3- sera strongly suggests a regulatory role for anti-V $\beta 5.1 \mathrm{Ab}$ 's.

In order to examine whether MG sera are able to inhibit the activation of $\mathrm{T}$ cells expressing a BV gene other than BV5S1, we designed an MLR-based assay using purified $T$ cell populations expressing different TCRs as responder cells against a pool of allogeneic cells from healthy donors as stimulator cells; we used MG sera or control sera as potential inhibitors of this MLR. Only the serum fraction bound to $T$ cells acted in this assay, since washes were introduced after preincubation of responder $T$ cells with serum before adding the stimulator cells. We show that the MG sera and not the control

\section{Figure 4}

sera fractions inhibited the MLR and that this effect was indeed specific for the V $\beta 5$.1-expressing cells, since it was not observed with purified V $\beta 2$-expressing cells (Figure $4 c)$ or V $\beta 14$-expressing cells (data not shown). A similar elegant MLR assay has been used previously to show that the mechanism of immunotherapy for maintaining pregnancy in recurrent spontaneous aborters treated by paternal lymphocytes is mediated by anti-TCR Ab's (58). In addition, the MG sera inhibited IFN- $\gamma$ secretion as quantified by ELISA in culture supernatants in the course of this MLR (Figure 4d). We also attempted to quantify IL-4,
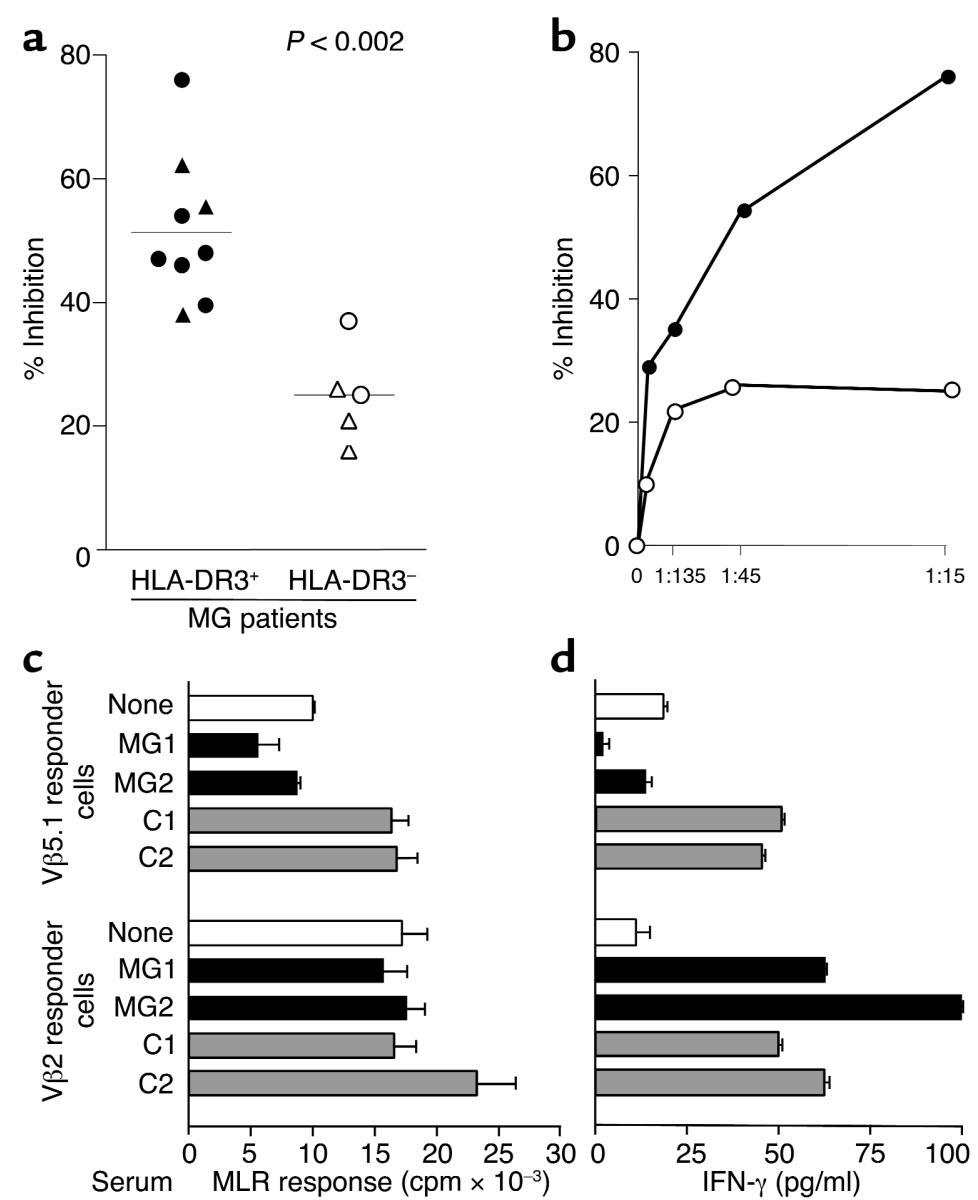

Functional effects of sera from EOMG patients. (a) Functional effects of sera from MG patients with or without HLA-DR3 on proliferative responses of a $\mathrm{V} \beta 5.1^{+} \mathrm{T}$ cell clone to AChR $\alpha 3-181$ in the presence of heat-inactivated sera of HLA-DR3 ${ }^{+}$ (filled shapes; $n=9$ ) or HLA-DR3-MG patients (open shapes; $n=5$ ). The data are presented as percent inhibition in the mean of duplicate wells. Results are from two independent experiments with sera from different MG patients (HLA-DR3 ${ }^{+}$ and $\mathrm{HLA}_{-\mathrm{Dr}}{ }^{-}$), with substantially similar results. In experiment 1 (triangles), we tested the MG sera at 1:10 with $2 \mathrm{ng} / \mathrm{ml} \mathrm{AChR} \alpha 3-181$ for 48 hours. In experiment 2 (circles) we tested MG sera at 1:15 with $0.6 \mathrm{ng} / \mathrm{ml}$ AChR $\alpha 3-181$ for 72 hours. The maximum responses (in the presence of healthy $A B$ serum) were $53,565 \mathrm{cpm}$ and 36,710 cpm for experiments 1 and 2, respectively. (b) Dose-dependent inhibition by representative sera from HLA-DR3 ${ }^{+}$(filled circles) or HLA-DR3- EOMG patients (open circles) from experiment 2 on the proliferative response of the V $\beta 5.1$ T cell clone to AChR $\alpha 3-181$. (c) Functional effects of the intact V $\beta 5.1$ cellbinding fraction from MG sera or from control sera in an MLR assay with purified V $\beta 5$.1-expressing cells as responder cells and a pool of allogeneic peripheral blood lymphocytes as stimulator cells on cell proliferation and (d) IFN- $\gamma$ secretion. 
but the levels were very low and under the lower detection limit of the calibration curve (data not shown). Thus, using this MLR inhibition assay we demonstrated both the specificity of action toward V $\beta 5$.1-expressing cells and a functional effect of MG sera, i.e., inhibition of cell proliferation and IFN- $\gamma$ secretion inhibition.

However, it can be predicted that the in vivo situation may be much more complicated. Several mechanisms of action of anti-TCR Ab's could be hypothesized: a direct binding to the TCR that inhibits the TCR-peptideMHC interaction, a functional inactivation without physical destruction (anergy), a specific deletion of pathogenic V $\beta 5.1$-expressing cells, or an immune deviation. The last two possibilities were shown to be effective in the SCID mouse model of MG when introducing an exogenous therapeutic monoclonal anti-V $\beta 5.1 \mathrm{Ab}$ (44). From the present study, it is clear that anti-V $\beta 5.1$ Ab's from MG sera are able to bind intact TCR on T cells, and that this binding mediates inhibition of both cell proliferation and cytokine secretion, whatever the antigen, autoantigen, or alloantigen, strongly suggesting that the anti-V $\beta 5.1 \mathrm{Ab}$ 's are absorbed by V $\beta 5.1$ expressing $\mathrm{T}$ cells within the patients themselves. In any case, the in vivo mechanism of action of anti-TCR Ab's that are spontaneously increased in the course of the disease remains to be elucidated. This question is now being addressed in the experimental model of MG where it is possible to perform physiological experiments in whole animals (namely transfers).

Conclusions and perspectives. It is well established that the development of autoimmune diseases hinges on the dynamic balance between effector and regulatory mechanisms, i.e., between self-reactive pathogenic $\mathrm{T}$ or $\mathrm{B}$ cells and regulatory $\mathrm{T}$ cells $(1,2)$. This demonstration of a spontaneous increase in the titer of anti-V $\beta 5.1 \mathrm{Ab}$ 's of the $\operatorname{IgG}$ isotype provides new insights into the natural mechanism regulating pathogenic autoreactive $T$ cells in $\mathrm{MG}$ and indicates that anti-V $\beta 5.1 \mathrm{Ab}$ 's play a protective role in $M G$ patients. Their presence, and the changes in their titer during the course of the disease, may reflect an immune response to pathogenic $\mathrm{T}$ cells expressing the $\mathrm{V} \beta 35.1$ gene according to an immune-surveillance mechanism. How these anti-TCR Ab's are raised is presently unknown, but the mechanism may rely on $\mathrm{T}$ cell homeostasis that maintains the overall size of the $T$ cell pool and the frequency of each $\mathrm{T}$ cell population at constant levels $(59,60)$. Anti-V 35.1 Ab's may act as regulators of the disease, targeting and controlling the excess of pathogenic V 35.1 -expressing T cells. However, there may be too few of these protective regulatory Ab's to control or halt a chronic, exacerbated autoimmune process, and it may therefore be necessary to boost the production of these protective $A b$ 's using peptides derived from V $\beta 5.1$ as vaccines. Our results do not indicate whether MG patients are deficient in this process of immune surveillance, but they do support the notion that the vaccination of MG patients with TCR peptides is feasible and potentially useful. The titer of anti-TCR Ab's may increase in HLA-DR $3^{+} \mathrm{MG}$ patients during a dynamic process designed to counteract the autoimmune response and aimed at controlling the excess of pathogenic $\mathrm{T}$ cells expressing $\mathrm{V} \beta 5.1$. They may play a protective role in $\mathrm{MG}$, helping to control the autoimmune reaction, with high anti-V $\beta 5.1 \mathrm{Ab}$ titers predictive of a favorable outcome in MG patients. This hypothesis, which is currently under investigation in experimental models of MG, is supported by our preliminary data.

The fact that the titers of these anti-TCR Ab's increase not only in autoimmune diseases (experimental and human) (15, 17-19), but also during the course of viral infections (53-55) or alloimmunization (58), supports the concept that the increase in anti-TCR Ab titer may play a role not only in the regulation of autoimmune responses (and diseases), but also more generally in the regulation of any immune response. We are currently investigating this possibility in an immune response model to elucidate the possible function of anti-TCR Ab's in immunoregulation and their relationship to $T_{\text {reg }}$ cells. Indeed, it is now demonstrated that TCR-reactive $T$ cells define a subset of the so-called regulatory $T$ cells that possess $\mathrm{T}_{\text {reg }}$ activity and are deficient in MS patients (61), providing a link between regulatory anti-TCR Ab's and regulatory anti-TCR T cells.

\section{Acknowledgments}

This work was supported by grants from the Association Française contre les Myopathies (AFM), the Centre National de la Recherche Scientifique (CNRS), the Caisse Nationale d'Assurance Maladie des Travailleurs Salariés (CNAMTS), and the European Community (QOL-2000-01918 and QLK3CT-2001-00225). Florence Jambou held doctoral fellowships from AFM. The sera from non-MG patients with clearly defined Ab's other than AChR were kindly provided by Angela Vincent (Neuroscience Group, Institute of Molecular Medicine, John Radcliffe Hospital). The irrelevant peptide from the IgG CDR2 region was kindly provided by Srinivas Kaveri of the Institut National de la Santé et de la Recherche Médicale (INSERM; U430, Institut des Cordeliers, Paris). We are grateful to Cyril Gaud and Philippe Levasseur for clinical evaluation of MG patients, and to Elisabeth Dulmet and Vincent Montpreville for histological analysis of MG thymi. We thank Nick Willcox (Neuroscience Group, Institute of Molecular Medicine, John Radcliffe Hospital), Srinivas Kaveri, and Abdelhadi Saoudi (INSERM U563, Purpan Hospital, Toulouse, France) for stimulating discussions, advice, and critical reading of the manuscript. We thank Hans Yssel for his advice and help in the design of experiments on the functional role of anti-TCR Ab's.

\footnotetext{
1. Seddon, B., and Mason, D. 2000. The third function of the thymus. Immunol. Today. 21:95-99.

2. Sagakuchi, S. 2000. Regulatory T cells: key controllers of immunologic self-tolerance. Cell. 101:455-458.

3. Vandenbark, A.A., Hashim, G.A., and Offner, H. 1996. T cell receptor peptides in treatment of autoimmune disease: rationale and potential. J. Neurosci. Res. 43:391-402.

4. Kumar, V., and Sercarz, E. 1999. Distinct levels of regulation in organspecific autoimmune diseases. Life Sci. 65:1523-1530.

5.Zipp, F., et al. 1998. Diversity of the anti-T-cell receptor immune
} 
response and its implications for T-cell vaccination therapy of multiple sclerosis. Brain. 121:1395-1407.

6. Cohen, I.R. 2001. T-cell vaccination for autoimmune disease: a panorama. Vaccine. 20:706-710.

7. Zang, Y.C., et al. 2000. Th2 immune regulation induced by $\mathrm{T}$ cell vaccination in patients with multiple sclerosis. Eur. J. Immunol. 30:908-913.

8. Kumar, V., et al. 1997. Recombinant T cell receptor molecules can prevent and reverse experimental autoimmune encephalomyelitis: dose effects and involvement of both CD4 and CD8 T cells. J. Immunol. 159:5150-5156.

9. Zhang, J., Medaer, R., Stinissen, P., Hafler, D., and Raus, J. 1993. MHCrestricted depletion of human myelin basic protein-reactive $T$ cells by $T$ cell vaccination. Science. 261:1451-1454

10. Hermans, G., Denzer, U., Lohse, A., Raus, J., and Stinissen, P. 1999. Cellular and humoral immune responses against autoreactive $T$ cells in multiple sclerosis patients after T cell vaccination. J. Autoimmun. 13:233-246.

11. Sun, D., Qin, Y., Chluba, J., Epplen, J.T., and Wekerle, H. 1988. Suppression of experimentally induced autoimmune encephalomyelitis by cytolytic T-T cell interactions. Nature. 332:843-845.

12. Kumar, V., and Sercarz, E. 1998. Induction or protection from experimental autoimmune encephalomyelitis depends on the cytokine secretion profile of TCR peptide-specific regulatory CD4 T cells. J. Immunol. 161:6585-6591.

13. Elias, D., Tikochinski, Y., Frankel, G., and Cohen, I.R. 1999. Regulation of NOD mouse autoimmune diabetes by $\mathrm{T}$ cells that recognize a TCR CDR3 peptide. Int. Immunol. 11:957-966.

14. Haqqi, T.M., Qu, X.M., Anthony, D., Ma, J., and Sy, M.S. 1996. Immunization with $\mathrm{T}$ cell receptor $\mathrm{V} \beta$ chain peptides deletes pathogenic $\mathrm{T}$ cells and prevents the induction of collagen-induced arthritis in mice. J. Clin. Invest. 97:2849-2858.

15. Marchalonis, J.J., et al. 1992. Human autoantibodies reactive with synthetic autoantigens from T-cell receptor $\beta$ chain. Proc. Natl. Acad. Sci. U. S. A. 89:3325-3329.

16. Hong, J., et al. 2000. Reactivity and regulatory properties of human antiidiotypic antibodies induced by $\mathrm{T}$ cell vaccination. J. Immunol. 165:6858-6864.

17. Bourdette, D.N., et al. 1994. Immunity to TCR peptides in multiple sclerosis. I. Successful immunization of patients with synthetic V $\beta 5.2$ and V $\beta 6.1$ CDR2 peptides. J. Immunol. 152:2510-2529.

18. Hashim, G.A., et al. 1992. Spontaneous development of protective anti$T$ cell receptor autoimmunity targeted against a natural EAE-regulatory idiotope located within the 39-59 region of the TCR-V beta 8.2 chain. J. Immunol. 149:2803-2809.

19. Hashim, G.A., et al. 1990. Antibodies specific for V $\beta 8$ receptor peptide suppress experimental autoimmune encephalomyelitis. J. Immunol. 144:4621-4627.

20. Berrih-Aknin, S. 1995. Myasthenia gravis, a model of organ-specific autoimmune disease. J. Autoimmun. 8:139-143.

21. Drachman, D.B. 1994. Myasthenia gravis. N. Engl. J. Med. 330:1797-1810.

22. Willcox, N. 1993. Myasthenia gravis. Curr. Opin. Immunol. 5:910-917.

23. Drachman, D.B., Adams, R.N., Josifek, L.F., and Self, S.G. 1982. Functional activities of autoantibodies to acetylcholine receptors and the clinical severity of myasthenia gravis. N. Engl. J. Med. 307:769-775.

24. Hoch, W., et al. 2001. Auto-antibodies to the receptor tyrosine kinase MuSK in patients with myasthenia gravis without acetylcholine receptor antibodies. Nat. Med. 7:365-368.

25. Vincent, A., Palace, J., and Hilton-Jones, D. 2001. Myasthenia gravis. Lancet. 357:2122-2128.

26. Newsom-Davis, J., et al. 1987. Immunological heterogeneity and cellular mechanisms in myasthenia gravis. Ann. N. Y. Acad. Sci. 505:12-26.

27. Engel, A.G. 1979. The immunopathological basis of acetylcholine receptor deficiency in myasthenia gravis. Prog. Brain Res. 49:423-434.

28. Lindstrom, J.M., Seybold, M.E., Lennon, V.A., Whittingham, S., and Duane, D.D. 1976. Antibody to acetylcholine receptor in myasthenia gravis. Prevalence, clinical correlates, and diagnostic value. Neurology. 26:1054-1059.

29. Compston, D.A., Vincent, A., Newsom-Davis, J., and Batchelor, J.R. 1980. Clinical, pathological, HLA antigen and immunological evidence for disease heterogeneity in myasthenia gravis. Brain. 103:579-601.

30. Levine, G.D., and Rosai, J. 1978. Thymic hyperplasia and neoplasia: a review of current concepts. Hum. Pathol. 9:495-515.

31. Berrih-Aknin, S., et al. 1987. The role of the thymus in myasthenia gravis: immunohistological and immunological studies in 115 cases. Ann. N. Y. Acad. Sci. 505:50-70.

32. Bofill, M., et al. 1985. Microenvironments in the normal thymus and the thymus in myasthenia gravis. Am. J. Pathol. 119:462-473.

33. Wakkach, A., et al. 1996. Expression of acetylcholine receptor genes in human thymic epithelial cells: implications for myasthenia gravis. J. Immunol. 157:3752-3760.

34. Wheatley, L.M., et al. 1992. Molecular evidence for the expression of nicotinic acetylcholine receptor alpha-chain in mouse thymus. J. Immunol. 148:3105-3109.

35. Salmon, A.M., Bruand, C., Cardona, A., Changeux, J.P., and Berrih-Aknin, S.
1998. An acetylcholine receptor $\alpha$ subunit promoter confers intrathymic expression in transgenic mice. Implications for tolerance of a transgenic selfantigen and for autoreactivity in myasthenia gravis. J. Clin. Invest. 101:2340-2350

36. Cohen-Kaminsky, S., Levasseur, P., Binet, J.P., and Berrih-Aknin, S. 1989. Evidence of enhanced recombinant interleukin-2 sensitivity in thymic lymphocytes from patients with myasthenia gravis: possible role in autoimmune pathogenesis. J. Neuroimmunol. 24:75-85.

37. Leprince, C., et al. 1990. Thymic B cells from myasthenia gravis patients are activated B cells. Phenotypic and functional analysis. J. Immunol. 145:2115-2122.

38. Moulian, N., et al. 1997. Thymocyte Fas expression is dysregulated in myasthenia gravis patients with anti-acetylcholine receptor antibody. Blood. 89:3287-3295.

39. Berrih-Aknin, S., et al. 1991. T-cell antigenic sites involved in myasthenia gravis: correlations with antibody titre and disease severity. J. Autoim mun. 4:137-153.

40. Melms, A., et al. 1988. Thymus in myasthenia gravis. Isolation of T-lymphocyte lines specific for the nicotinic acetylcholine receptor from thymuses of myasthenic patients. J. Clin. Invest. 81:902-908.

41. Sommer, N., Willcox, N., Harcourt, G.C., and Newsom-Davis, J. 1990. Myasthenic thymus and thymoma are selectively enriched in acetylcholine receptor-reactive T cells. Ann. Neurol. 28:312-319.

42. Molnar, J., and Szobor, A. 1990. Myasthenia gravis: effect of thymectomy in 425 patients. A 15-year experience. Eur. J. Cardiothorac. Surg. 4:8-14

43. Truffault, F., Cohen-Kaminsky, S., Khalil, I., Levasseur, P., and BerrihAknin, S. 1997. Altered intrathymic T-cell repertoire in human myasthenia gravis. Ann. Neurol. 41:731-741.

44. Aissaoui, A., et al. 1999. Prevention of autoimmune attack by targeting specific $\mathrm{T}$ cell receptor in a severe combined immunodeficiency mouse model of myasthenia gravis. Ann. Neurol. 46:559-567.

45. Vieira, M.L., et al. 1993. Identification by genomic typing of non-DR3 HLA class II genes associated with myasthenia gravis. J. Neuroimmunol. 47:115-122.

46. Morel, E., et al. 1982. Assay of acetylcholine receptor antibodies in myasthenia gravis. A study of 329 sera [in French]. Nowv. Presse Med. 11:1849-1854.

47. Jaretzki, A., III, et al. 2000. Myasthenia gravis: recommendations for clinical research standards. Task Force of the Medical Scientific Advisory Board of the Myasthenia Gravis Foundation of America. Ann. Thorac Surg. 70:327-334

48. Cathala, H.P. 1980. Electrological contribution to diagnosis of myasthenia gravis. Ann. Chir. 34:159-160.

49. Kaveri, S., Kang, C.Y., and Kohler, H. 1990. Natural mouse and human antibodies bind to a peptide derived from a germline $\mathrm{VH}$ chain. Evidence for evolutionary conserved self-binding locus. J. Immunol. 145:4207-4213.

50. Hermanson, G.T. 1996. Glutaraldehyde-mediated hapten carrier conjugation. In Bioconjugate techniques. Academic Press. San Diego, California, USA. $453-454$

51. Ong, B., et al. 1991. Critical role for the Val/Gly ${ }^{86}$ HLA-DR $\beta$ dimorphism in autoantigen presentation to human T cells. Proc. Natl. Acad. Sci. U. S. A 88:7343-7347.

52. Adorini, L., et al. 1990. New perspectives on immunointervention in autoimmune diseases. Immunol. Today. 11:383-386.

53. Dehghanpisheh, K., and Marchalonis, J.J. 1997. Retrovirally induced mouse anti-TCR monoclonals can synergize the in vitro proliferative $\mathrm{T}$ cell response to bacterial superantigens. Scand. J. Immunol. 45:645-654.

54. Marchalonis, J.J., et al. 1997. Analysis of autoantibodies to T-cell receptors among HIV-infected individuals: epitope analysis and time course. Clin. Immunol. Immunopathol. 82:174-189.

55. Liang, B., Marchalonis, J.J., Zhang, Z., and Watson, R.R. 1996. Effects of vaccination against different $T$ cell receptors on maintenance of immune function during murine retrovirus infection. Cell. Immunol. 172:126-134.

56. Kaymaz, H., Dedeoglu, F., Schulter, S.F., Edmundson, A.B., and Marchalonis, J.J. 1993. Reactions of anti-immunoglobulin sera with synthetic $T$ cell receptor peptides: implications for the three-dimensional structure and function of the TCR beta chain. Int. Immunol. 5:491-502.

57. Kumar, V., and Sercarz, E.E. 1993. The involvement of T cell receptor peptide-specific regulatory CD4 $+\mathrm{T}$ cells in recovery from antigeninduced autoimmune disease. J. Exp. Med. 178:909-916.

58. Ito, K., Tanaka, T., Tsutsumi, N., Obata, F., and Kashiwagi, N. 1999. Possible mechanisms of immunotherapy for maintaining pregnancy in recurrent spontaneous aborters: analysis of anti-idiotypic antibodies directed against autologous T-cell receptors. Hum. Reprod. 14:650-655.

59. Van Parijs, L., and Abbas, A.K. 1998. Homeostasis and self-tolerance in the immune system: turning lymphocytes off. Science. 280:243-248.

60. Freitas, A.A., and Rocha, B. 2000. Population biology of lymphocytes: the flight for survival. Annu. Rev. Immunol. 18:83-111.

61. Vandenbark, A.A., et al. 2002. Regulation of autoimmunity with TCR peptides: latest breakthroughs. Sixth International Symposium on the Immunotherapy of the Rheumatic Diseases. http://www.kcl.ac.uk/ip/ jeremycridland/rsymp/abstracts-04.htm. (Abstr.) 